\title{
Removing a broken guidewire in the hip joint: treatment options and recommendations for preventing an avoidable surgical catastrophe. A case report
}

Removendo um fio-guia quebrado na articulação do quadril: opções de tratamento e recomendações para prevenir uma evitável catástrofe cirúrgica. Um relato de caso

Abhijeet Ashok Salunkel, Prem Haridas Menon", Gurunathampalayam Ilango Nambi"', Junhao Tan'v, Vivek Patelv, Yongsheng Chen ${ }^{\mathrm{VI}}$, Jay Kumar ${ }^{\mathrm{VII}}$

Department of Orthopedics and Traumatology, Pramukswami Medical College, Karamsad, Anand, Gujarat, India

'MD. Clinical Fellow, Division of Musculoskeletal Oncology, National University Hospital, Singapore. Assistant Professor, Department of Orthopedics, Pramukswami Medical College,

Karamsad, Anand, Gujarat, India.

"MD. Clinical Fellow, Department of Orthopedics, National University Hospital, Singapore.

"'MD. Consultant, Department of Plastic \& Reconstructive Microvascular Services, Kovai Medical Center \& Hospital, Coimbatore, Tamil Nadu, India.

"Medical Student, Yong Lin Loo School of Medicine, National University of Singapore, Singapore.

vMD. Assistant Professor, Department of Orthopedics and Traumatology, Pramukswami Medical College, Karamsad, Anand, Gujarat, India.

"MD. Resident, Hand \& Reconstructive Microsurgery Cluster, Department of Orthopedics, National University Hospital, Singapore.

VIIMD. Resident, Department of Orthopedics and Traumatology, Pramukswami Medical College, Karamsad, Anand, Gujarat, India.

\section{KEY WORDS:}

Hip fractures.

Pelvis.

Hip joint.

Bone wires.

Bone nails.

\section{PALAVRAS-CHAVE:}

Fraturas do quadril.

Pelve.

Articulação do quadril.

Fios ortopédicos.

Pinos ortopédicos.

\begin{abstract}
CONTEXT: Hardware breakage during hip surgery can pose challenging and difficult problems for orthopedic surgeons. Apart from technical difficulties relating to retrieval of the broken hardware, complications such as adjacent joint arthritis and damage to neurovascular structures and major viscera can occur. Complications occurring during the perioperative period must be informed to the patient and proper documentation is essential. The treatment options must be discussed with the patient and relatives and the implant company must be informed about this untoward incident.

CASE REPORT: We report a case of complete removal of the implant and then removal of the broken guidewire using a combination of techniques, including a cannulated drill bit, pituitary forceps and Kerrison rongeur.

CONCLUSIONS: We suggest some treatment options and recommendations for preventing an avoidable surgical catastrophe.
\end{abstract}

\section{RESUMO}

CONTEXTO: Ruptura de material de síntese durante a cirurgia de quadril pode representar problemas desafiadores e difíceis para cirurgiões ortopédicos. Além de dificuldades técnicas com recuperação do material quebrado, complicações como artrite na articulação adjacente, danos às estruturas neurovasculares e às principais vísceras podem ocorrer. A complicação durante o período perioperatório deve ser informada ao paciente e documentação apropriada é essencial. As opções de tratamento devem ser discutidas com o paciente e seus familiares e a empresa do implante deve ser informada sobre este incidente desagradável. RELATO DE CASO: Nós relatamos um caso da remoção completa do implante e, em seguida, a remoção do fio-guia quebrado usando uma combinação de técnicas, incluindo uma broca canulada, fórceps da hipófise e rongeur de Kerrison.

CONCLUSÕES: Sugerimos algumas opções de tratamento e recomendações para prevenir uma evitável catástrofe cirúrgica. 


\section{INTRODUCTION}

Hardware breakage during hip surgery can pose challenging and difficult problems for orthopedic surgeons. Apart from technical difficulties relating to retrieval of the broken hardware, complications such as adjacent joint arthritis and damage to neurovascular structures and major viscera have also been described. ${ }^{1-4}$ Previously reported techniques for removing broken guidewires in the hip joint include use of over-reaming, use of disc forceps, arthroscopically assisted methods and arthrotomy of the hip joint. In this article, we report a case of complete removal of the implant and then removal of the broken guidewire using a combination of techniques including a cannulated drill bit, pituitary forceps and Kerrison rongeur.

\section{CASE REPORT}

A 65-year-old woman presented with left hip pain following trivial trauma. She was found to have sustained an Evan's type 4 left intertrochanteric hip fracture (Figure 1). The patient had diabetes and hypertension, which were well controlled with oral medication. We decided to fix the fracture surgically using a proximal intramedullary femoral nail. The patient underwent surgery on the third day after the injury.

During the surgery, the patient underwent routine uneventful combined spinal and epidural anesthesia. She was positioned supinely on a standard orthopedic fracture table. Closed reduction of the left intertrochanteric hip fracture was performed under image guidance. The surgeon performed a standard skin incision at $5 \mathrm{~cm}$ proximally to the tip of the greater trochanter, in line with the long axis of the femur. The entry point was into the lateral aspect of the greater trochanter, as per our usual practice. After reaming, a short proximal femoral nail was inserted easily. Two guidewires were then placed with the aid of the insertion device, to guide the insertion of the recon screws. A distal hip screw was subsequently placed successfully.

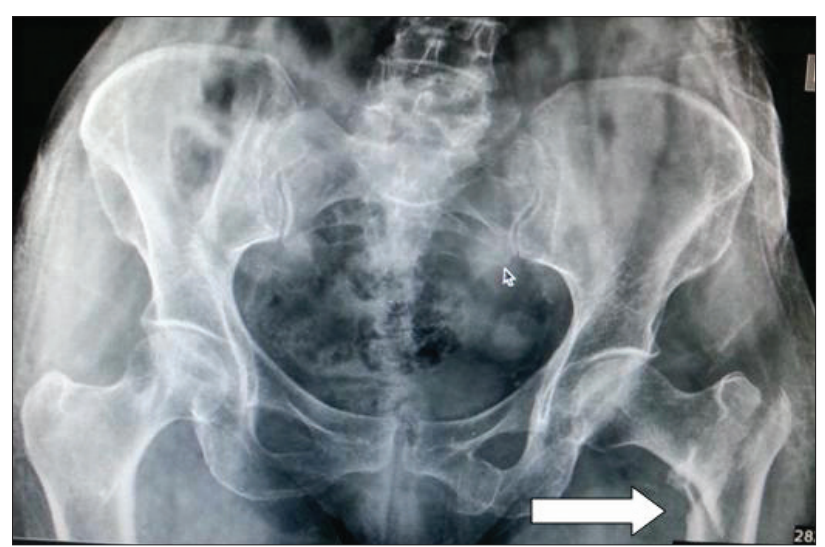

Figure 1. Preoperative radiograph showing Evan's type 4 left intertrochanteric hip fracture (white arrow).
However, during the placement of the proximal hip screw over the cannulated guidewire, a sudden loss of resistance was unexpectedly encountered. Intraoperative images were immediately obtained and the guidewire was found to have broken with its tip lying within the subchondral area of the femoral head. The broken guidewire had not breached the hip joint. The surgeon therefore decided to leave the guidewire alone, with no further attempt at removing it.

On postoperative day two, plain radiographs were produced, which revealed that the broken guidewire had migrated proximally into the hip joint (Figure 2). The patient therefore underwent a repeat procedure in an attempt to remove the broken guidewire. We began the revision surgery by removing the proximal hip screw. We attempted to reach the broken guide wire with the aid of a cannulated drill bit but we were unable to retrieve the broken wire. We then tried to use the pituitary forceps and Kerrison rongeur to remove the broken guide. Both of the above attempts at removing the broken guidewire were unsuccessful, so we removed the distal hip screw, distal locking screw and intramedullary nail. After complete removal of all other implants, the existing track from the proximal recon screw was enlarged using a cannulated drill bit. We were able to partially engage the tip of the guidewire with the cannulated drill bit. This allowed us to

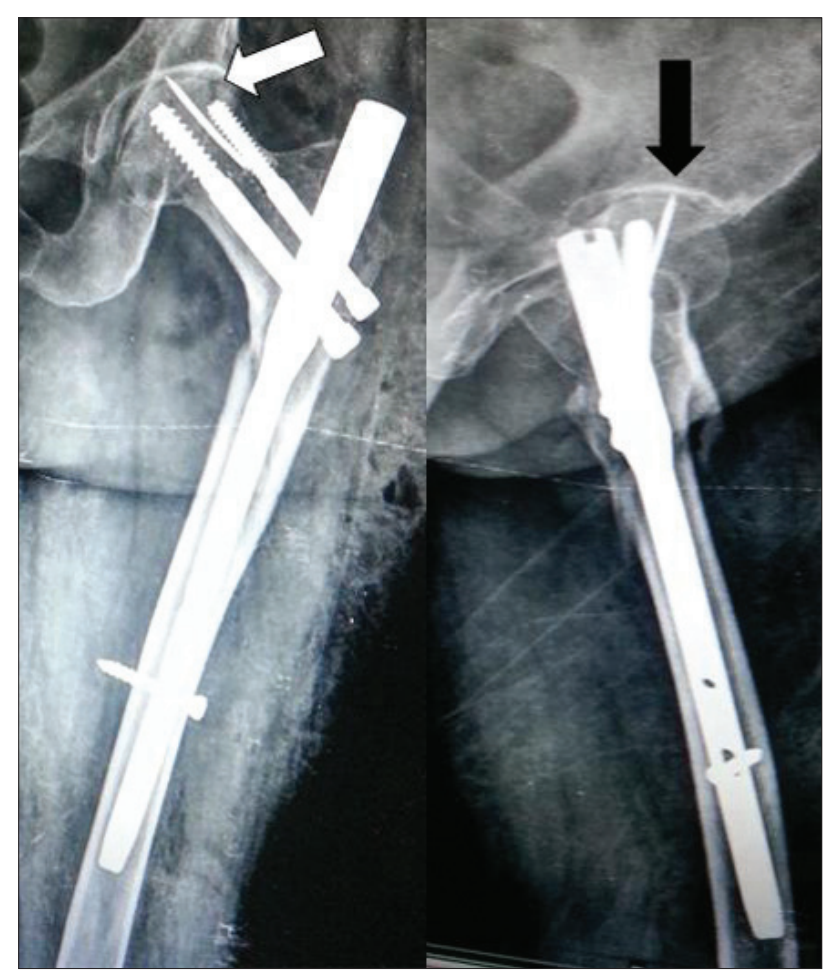

Figure 2. Postoperative radiographs produced after the primary surgery in anteroposterior view (white arrow) and lateral view (black arrow), showing broken guidewire in hip joint and short femoral nail. 
reverse the guidewire slightly into the track. Once the track was large enough, a $2 \mathrm{~mm}$ pituitary rongeur and Kerrison rongeur were used successively to grasp the tip of the broken guidewire and remove it. Following successful retrieval of the broken guidewire, a long proximal femoral intramedullary nail was inserted to achieve fracture fixation (Figure 3).

The patient was mobilized with partial weight-bearing on the third postoperative day. Her postoperative recovery was uneventful and she was discharged five days after the revision procedure. She underwent routine follow-up in the outpatient clinic. By three months after the operation, her fracture had completely united and she was walking independently without support.

\section{DISCUSSION}

We searched for similar cases in different databases (PubMed and Lilacs database) using the terms: "hip joint" AND "guide wire" AND "breakage" (Table 1). We found that few cases have been published. Abstracts or full texts were analyzed and it was seen that less than 20 reports were similar to ours (Table 2). ${ }^{4-9}$ This literature review suggests that the most commonly broken orthopedic hardware is the drill bit, followed by guidewires. The complications caused by broken hardware include adjacent joint arthritis and damage to neurovascular

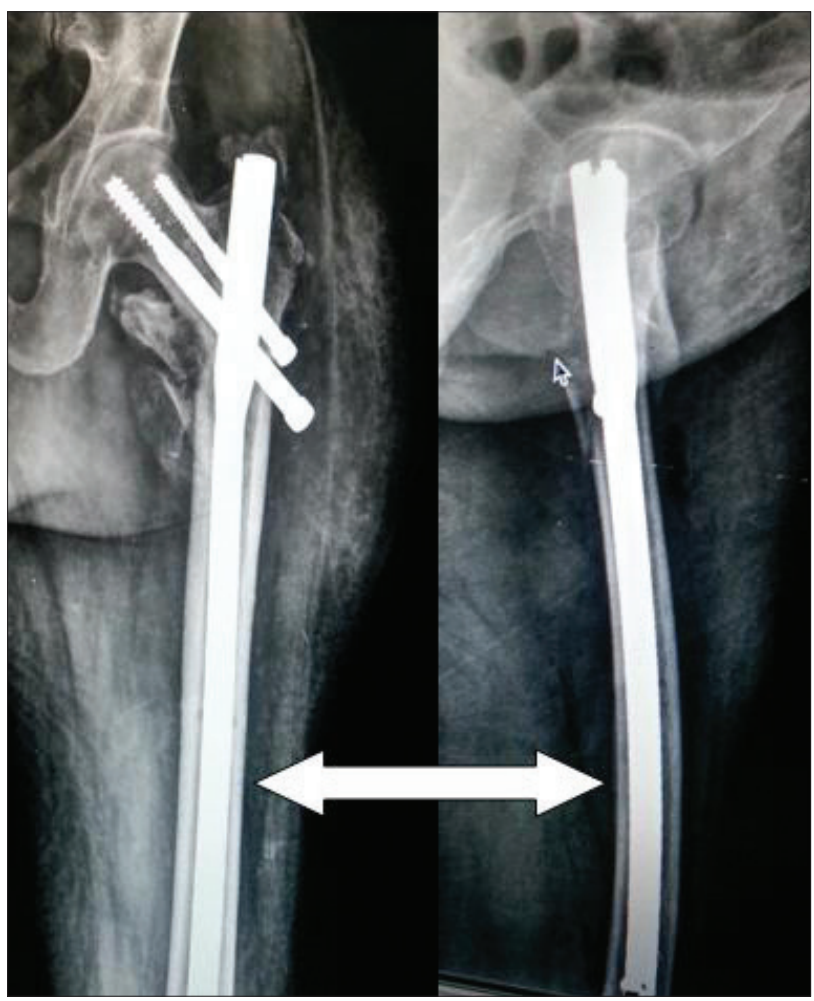

Figure 3. Postoperative radiographs produced after revision surgery, showing that the broken guidewire was removed and a long femoral nail was inserted (white arrow). structures and major viscera. Hardware may break through reuse, or due to technical problems such as drilling at a low angle of incidence or inadvertent bending during insertion. Price et al. and Sharma et al. studied the reasons for hardware failure due to repeated use of guidewires. They suggested that repeated use of guidewires over time causes deformation and loss of bending and torsional strength, such that the chances of failure increase while drilling and inserting a screw over the wire. ${ }^{5,6}$ In addition, technical errors that predispose towards intraoperative guidewire breakage may be due to inadvertent changes in direction and twisting during insertion, penetration of the subchondral bone into the hip joint, or insertion of a reamer or screw improperly at an angle to the guidewire, thereby causing excessive contact stress.

The known methods of removing of broken guidewires include use of over-reaming, use of pituitary forceps, arthroscopically assisted methods of retrieval and open arthrotomy and dislocation of the hip joint. ${ }^{6-9}$

It has been shown that the cross-sectional shape of the guidewire changes from round to oval following breakage. ${ }^{9}$ This was perhaps the reason why we were able to use the cannulated drill bit to engage the broken guide wire, to assist in its removal in the present case.

Table 1. Results from review of the literature in medical databases for case reports and case series regarding hip fractures with implant breakage. Search conducted on September 10, 2014

\begin{tabular}{|c|c|c|c|}
\hline Database & Search strategies & $\begin{array}{l}\text { Papers } \\
\text { found }\end{array}$ & $\begin{array}{l}\text { Papers } \\
\text { related }\end{array}$ \\
\hline $\begin{array}{l}\text { Medline (Via } \\
\text { PubMed) }\end{array}$ & $\begin{array}{c}\text { ((bone wires) OR (guide wire) } \\
\text { OR (guide wires)) AND (hip } \\
\text { joint) }\end{array}$ & 27 & 9 \\
\hline Lilacs database & $\begin{array}{c}\text { ((bone wires) OR (guide wire) } \\
\text { OR (guide wires)) AND (hip } \\
\text { joint) }\end{array}$ & 35 & 7 \\
\hline
\end{tabular}

Table 2. Review of the literature regarding implant removal from hip joint

\begin{tabular}{|c|c|c|c|}
\hline Author & Year & $\begin{array}{l}\text { Method of removing broken } \\
\text { implant from hip joint }\end{array}$ & Comments \\
\hline $\begin{array}{l}\text { Sharma } \\
\text { et al. }{ }^{6}\end{array}$ & 2008 & Dynamic hip screw reamer & \\
\hline Sen et al. ${ }^{7}$ & 2010 & Laparotomy & $\begin{array}{l}\text { Two cases of implant } \\
\text { breakage, in hip joint } \\
\text { and pelvis respectively }\end{array}$ \\
\hline $\begin{array}{l}\text { Peivandi } \\
\text { et al. }{ }^{9}\end{array}$ & 2011 & Cannulated drill bit & \\
\hline $\begin{array}{l}\text { Current } \\
\text { study }\end{array}$ & 2014 & $\begin{array}{l}\text { Implant removal using } \\
\text { pituitary rongeur, Kerrison } \\
\text { rongeur and cannulated } \\
\text { drill bit }\end{array}$ & $\begin{array}{l}\text { A combination of } \\
\text { methods was used for } \\
\text { removing the broken } \\
\text { implant }\end{array}$ \\
\hline
\end{tabular}


Another technique that has been described is that of overreaming. This method uses a larger reamer, such as that of a dynamic hip screw reamer, to provide access to the broken guidewire. The main disadvantage of over-reaming is that it leads to formation of large bone defects, which predispose towards development of pathological fractures.

The method that we used in the present case included firstly complete removal of the implant and then removal of the broken guidewire using a combination of techniques including a cannulated drill bit, pituitary forceps and Kerrison rongeur. The disadvantage of our technique was that removal of the implant led to loss of the reduction of the fracture. Fortunately, the fracture pattern was readily amenable to closed reduction and therefore did not pose much difficulty. A long femoral nail was used for re-fixation, in order to achieve better stability.

Finally, arthrotomy and hip dislocation is the last resort for removal of broken guidewires. The complications from this method include loss of fracture reduction, avascular necrosis of the hip and an increased chance of recurrent hip dislocation, especially if an extensive approach is used.

Complications that occur during the perioperative period must be informed to the patient and proper documentation is essential. The treatment options must be discussed with the patient and relatives.

Furthermore, the implant company must be informed about this untoward incident. ${ }^{10}$

\section{Clinical recommendations}

- Use new guidewires for every new case of nailing of long bones.

- Avoid unintended changes of direction and bending during insertion of the guidewire, reaming and screw insertion.

- Give proper counseling to the patient and relatives about perioperative complications and their consequences and treatment.

- Produce proper documentation of perioperative complications and report the occurrence to the implant company.

\section{CONCLUSIONS}

The methods for retrieval of broken guidewires in the hip joint include use of over-reaming, use of pituitary forceps, use of Kerrison rongeur, arthroscopically assisted methods, complete removal of implant prior to retrieval of broken hardware and arthrotomy of the hip joint. Occasionally, a combination of the above techniques has to be used to achieve successful removal of the broken hardware.

\section{REFERENCES}

1. Medved I, Simic O, Bralic M, et al. Chronic heart perforation with 13.5 cm long Kirschner wire without pericardial tamponade: an unusual sequelae after shoulder fracture. Ann Thorac Surg. 2006;81(5):1895-7.
2. Brodell JD, Leve AR. Disengagement and intrapelvic protrusion of the screw from a sliding screw-plate device. A case report. J Bone Joint Surg Am. 1983;65(5):697-701.

3. Mishra P, Jain P, Aggarwal A, et al. Intrapelvic protrusion of guide wire during fixation of fracture neck of femur. Injury. 2002;33(9):839-41.

4. Hirt U, Auer JA, Perren SM. Drill bit failure without implant involvement--an intraoperative complication in orthopaedic surgery. Injury. 1992;23 Suppl 2:S5-16.

5. Price MV, Molloy S, Sollan MC, Sutton A, Ricketts DM. The rate of instrument breakage during orthopaedic procedures. Int Orthop. 2002;26(3):185-7.

6. Sharma H, Chauhan M, Maini L. A technique to remove a broken guide wire transfixing the hip joint. Acta Orthop Belg. 2008;74(5):683-5.

7. Sen RK, Tripathy SK, Aggarwal S, et al. Broken Kirschner or guide-wire retrieval: a report of 4 cases. Hip Int. 2010;20(4):551-4.

8. Docquier PL, Manche E, Autrique JC, Geulette B. Complications associated with gamma nailing. A review of 439 cases. Acta Orthop Belg. 2002;68(3):251-7.

9. Peivandi MT, Kachooei AR, Nazemian Z. New method to remove a broken guide pin in the hip joint. Orthopedics. 2011;34(10):e685-7.

10. Sayegh FE, Tsintzas D, Kapetanos GA. Intrapelvic migration of a guide pin during fixation of a hip fracture: who and what is to blame? Acta Orthop Belg. 2005;71(2):239-41.

Source of funding: None

Conflict of interests: None

Date of first submission: June 3, 2014

Last received: September 11, 2014

Accepted: September 25, 2014

Address for correspondence:

Abhijeet Ashok Salunke

Assistant Professor \& Consultant Orthopedic Oncosurgeon, Department of Orthopedics

Pramukswami Medical College — Karamsad 388325

Anand - Gujarat — India

Tel: 919726500263

E-mail: drabhijeetsalunke@gmail.com 